ALTERIDADES, 2020, 30 (60): Págs. 105-1 16 www.doi.org/ $10.24275 / \mathrm{uam} / \mathrm{izt} / \mathrm{dcsh} / \mathrm{alt} / 2020 v 30$ n60 / Gil

\title{
Los tres cuerpos: la influencia de la MIB en los matrimonios rarámuri*
}

\section{The three bodies: the MIB's influence on raramuri marriages}

GABRIELA GIL VELOZ**

\begin{abstract}
Bawinokachi Indigenous Mission (MIB) was founded in 1952 by Ana García Narro in the Sierra Tarahumara, with the desire to evangelize and educate the rarámuri. The legacy of "Anita" continues with missionaries influencing life in different areas of the community: social, political, cultural, personal and individual. This article will analyze generational changes in marriage (arrejuntamientos) through the three bodies theoretical perspective (Scheper-Hughes and Lock, 1987). The text presents marriages through three rarámurigenerations, historically interconnected by different contexts such as sowing, grazing, sawmills, seasonal migration and drug trafficking. The social body and the normativity of the political body mediate the first two generations; whereas the individual body does so in the last one. The three bodies interrelate and dialogue with each other. Key words: arrejuntamiento, migration, missions, drug trafficking, sierra tarahumara, generations
\end{abstract}

\begin{abstract}
Resumen
La Misión Indígena Bawinokachi (MIB) fue fundada en 1952 por Ana García Narro en la Sierra Tarahumara, con el deseo de evangelizar y alfabetizar a los rarámuri. El legado de "Anita" continuó; los misioneros incidieron en la vida de la comunidad en diferentes ámbitos: social, político, cultural, personal e individual. Este artículo analiza los cambios generacionales en los arrejuntamientos desde la perspectiva teórica de los tres cuerpos (Scheper-Hughes y Lock, 1987). Se presentan los matrimonios en tres generaciones rarámuri, atravesados históricamente por diversos contextos: la siembra, el pastoreo, los aserraderos, la migración estacional y el narcotráfico. Las primeras dos generaciones están mediadas por el cuerpo social y la normatividad del cuerpo político; la última, por el cuerpo individual. Los tres cuerpos se interrelacionan y dialogan unos con otros.
\end{abstract}

Palabras clave: arrejuntamiento, migración, misiones, narcotráfico, sierra tarahumara, generaciones

\footnotetext{
* Artículo recibido el 17/09/19 y aceptado el 11/02/20.

** Centro de Investigaciones y Estudios Superiores en Antropología Social, Unidad Occidente. Av. España 1359, col. Moderna, 44190 Guadalajara, Jal. <gabygilv@hotmail.com>. oRcID: https: / / orcid.org/0000-0003-4269-4656.
} 
...todo puede simbolizar al cuerpo y el cuerpo puede simbolizarlo todo...

Mary Douglas

\section{Introducción}

$\mathrm{D}$ urante los últimos 70 años, la comunidad rarámuri de Ba'winokáachi ${ }^{1}$ ha pasado por cambios significativos en sus modos y ciclo de vida, que han ido adaptando a diversas situaciones como la llegada, hace más de 100 años, de los aserraderos y la industria maderera porfirista (Salazar, 2006) que acabó con el bosque. Cuando se agotó esta fuente de trabajo, se iniciaron las migraciones estacionales a la pizca de manzana, mismas que con el tiempo adquirirían carácter permanente. Recientemente, el narcotráfico empezó a ser una fuente de empleo.

Además de los aserraderos, la migración y el narcotráfico, en Ba'winokáachi existe una intervención de larga duración: la Misión. Esta institución ha tenido presencia desde 1952, y ha sido fundamental para la consolidación de la comunidad. Entretejidas con el curso de la historia regional, observo tres grandes etapas de la Misión: la de Anita -de 1952 a su muerte en 1986-; la de misioneros con carisma marista-de 1986 a 2001-; y la de coordinaciones heterogéneas -de 2001 a 2020.

Los cambios generacionales y las condiciones de las últimas décadas invitan a reflexionar de qué manera se refleja el contexto en los matrimonios-que ellos llaman "arrejuntarse" o napawima en lengua rarámuri- a lo largo de tres generaciones, y cómo podemos analizarlo desde las tres dimensiones del cuerpo: individual, social y política. Así pues, el objetivo de este texto es analizar, reflexionar y dialogar los cambios intergeneracionales del arrejuntarse, tomando en cuenta el cuerpo individual, el cuerpo social y el cuerpo político planteados por Scheper-Hughes y Lock (1987). Con el cuerpo individual examino y recupero la experiencia vivida, desde el cuerpo social, la representación simbólica de la organización social, y con el cuerpo político la normativa y el control social.

\section{La Misión Indígena Bawinokachi}

Ba'winokáachi está conformada por once rancherías. $\mathrm{El}$ centro rarámuri es Ba'winokáachi, con las ranche- rías cercanas: El Rincón y El Entronque; Totorí, Cerro Pelón, Ojo de Buey, Egochi, a una distancia media; y, finalmente, El Maguey o Magueyitos, La Mesa del Ojito, Wiyochi y El Piloncillo, las más alejadas (mapa 1).

Ba'winokáachi es una comunidad de reciente formación, la población comenzó con un aserradero, y se consolidó con la llegada de Ana García Narro en 1952, quien fundó la Misión Indígena Bawinokachi (мів). Los jesuitas y los hermanos maristas de Sisoguichi empezaron a visitarla y ayudarla. Al poco tiempo, los maristas comenzaron a llevar, durante los veranos, a jóvenes de Guadalajara, quienes auxiliaban a Anita. A su muerte el 12 de mayo de 1986, uno de estos jóvenes se hizo cargo de la misión:

Muchos muchachos se empezaron a enamorar de Ba'winokáachi y empezaron a venir con más regularidad. En aquel tiempo eran muchachitos de prepa, cuando terminaron su carrera, unos de ellos dijeron "antes de empezar a trabajar, quiero irme unos dos, tres meses con Anita" y en esos dos, tres meses se muere Anita. Los gobernadores le dicen a Checo Vega "quédate, no te vayas" él tuvo que hacer un discernimiento y aceptó. Empezaron entonces ya el grupo de voluntarios y los maristas asumieron la responsabilidad de llevar adelante la obra, con sus pros, sus contras, sus subidas y sus bajadas. ${ }^{2}$

Con Checo Vega empezaron las comunidades misioneras de alrededor de diez jóvenes, relacionados con los maristas. Anita regalaba ropa, despensas y cobijas. Los misioneros vendían las artesanías de las mujeres (ollas de barro), basados en un sistema de trueque por comida. Con el paso del tiempo la Misión ha dejado de regalar cosas. El siguiente cuadro presenta a los coordinadores de la Misión, divididos en tres grandes etapas: el periodo de Anita de 1952 a1986, la con solidación de la Misión de 1986 a 2001, y la migración y coordinaciones heterogéneas de 2001 a 2020 (véase cuadro 1).

\section{La noción rarámuri de cuerpo}

La literatura especializada en la noción de cuerpo entre los rarámuri tiene como denominador común la categoría de persona. Isabel Martínez -"Los caminos rarámuri. Persona y cosmos en el noreste de México" (2008)- utiliza el concepto de cuerpo para acceder a la noción de persona, que considera un instrumento

1 Ba’winokáachi es el nombre correcto, sin embargo el clero escribe Bawinokachi y el Instituto Nacional de Estadística y Geografía (INEGI) Bahuinocachi.

2 Entrevista con Javier Ávila Aguirre ("Pato"), sacerdote jesuita, el 5 de diciembre de 2013 en Creel, Sierra Tarahumara, Chihuahua. 
Mapa 1. Comunidad de Ba'winokáachi
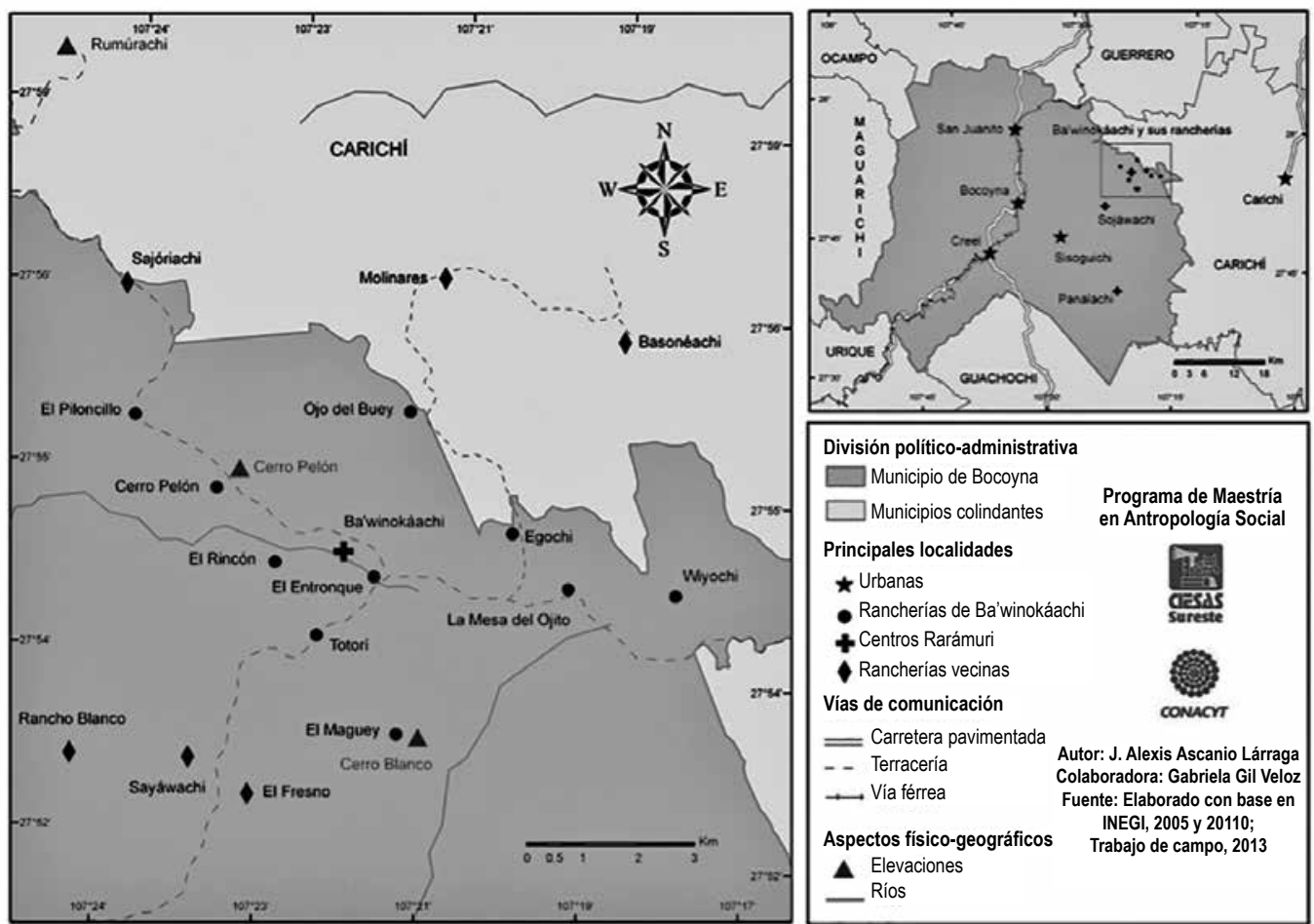

División político-administrativa

$\square$ Municipio de Bocoyna

$\square$ Municipios colindantes

Programa de Maestría

Principales localidades

$\star$ Urbanas

- Rancherías de Ba'winokáachi

+ Centros Rarámuri

- Rancherías vecinas

Vías de comunicación

= Carretera pavimentada

_. Terracería

$\longrightarrow$ Via férrea

Aspectos físico-geográficos

$\boldsymbol{\Delta}$ Elevaciones

Ríos

Cuadro 1. Histórico de coordinadores de la MIв

\begin{tabular}{|c|c|c|c|}
\hline & & Periodo & Años \\
\hline \multicolumn{4}{|c|}{ Primera etapa, 34 años } \\
\hline 0 & Ana García Narro & 1952-1986 & 34 \\
\hline \multicolumn{4}{|c|}{ Segunda etapa, 15 años } \\
\hline 1 & Sergio "Checo" Vega & 1986-1988 & 2 \\
\hline 2 & Juan Paulo “Papayo” Romero e Imelda Borunda* & 1988-1993 & 5 \\
\hline 3 & Rafael Palos y Yolanda Gudiño & 1993-1994 & 1 \\
\hline 4 & Álvaro Padilla y Lourdes Ramos & 1994-1997 & 3 \\
\hline 5 & Fernando Pamplona & $1998-2000$ & 2 \\
\hline 6 & Álvaro Padilla y Lourdes Ramos & $2000-2001$ & 1 \\
\hline \multicolumn{4}{|c|}{ Tercera etapa, 19 años } \\
\hline 7 & Efraín Jiménez & $2001-2004$ & 3 \\
\hline 8 & Adriana Acosta & 2004-2007 & 3 \\
\hline 9 & Mónica Massini* & 2007 & 2 meses \\
\hline 10 & Jesús Aguirre y María Pontes* & 2007-2008 & 1 \\
\hline 11 & Teresa Orvañanos & 2008-2009 & 1 \\
\hline 12 & Hno. Álvaro Barragán y Sergio Leal "Choco”* & 2009 & 3 meses \\
\hline 13 & Luis Hernández & 2010 & 1 \\
\hline 14 & Cristina García y Otanio “Tano” Rascón & $2010-2016$ & 7 \\
\hline 15 & Mayela González* & $2017-2020$ & 3 \\
\hline
\end{tabular}

* Exalumnos maristas. 
de organización de la experiencia social. Sin embargo, para los rarámuri la reflexión sobre el cuerpo está inmersa en una preocupación de mayor amplitud. La persona está compuesta por el cuerpo (repokára) y las almas (alewá); así, la persona rarámuri es parte de un todo social y de un cosmos en el que sus acciones van más allá de un sujeto y de una colectividad, para situarse dentro de un entramado social que le permite ser único y social (Guillén y Martínez, 2005: 229).

Ángel Acuña (2006: 445) escribe sobre la construcción social del cuerpo en movimiento y de los usos y técnicas del cuerpo que propone Mauss (1979), y define a la persona rarámuri como la que percibe un mundo dual, clasificado en opuestos:

El principio masculino se asocia con el número tres, estar arriba, la luz, el sol, el día, el color rojo, el norte, el lado derecho; el principio femenino lo hace por su parte con el lado izquierdo con el número cuatro, estar abajo, la luna, la noche, la obscuridad, el color negro, el sur, el lado izquierdo. Hombre y mujer conjugan o intercalan sus caracteres opuestos con el propósito de mantenerse en equilibrio. En sintonía con la concepción dual del mundo, el cuerpo refleja ese dualismo, siendo así su réplica a pequeña escala. La corporeidad del hombre y la mujer rarámuri se caracteriza por la complementariedad [...] la mujer no corre con bola como el hombre, lo hace con ariweta, y no porque no esté capacitada sino porque hay que hacerlo distinto [Acuña, 2006: 445].

Alejandro Fujigaki -Muerte y persona: Ensayo sobre rituales mortuorios en una comunidad de la Sierra Tarahumara (2005)- presenta el antecedente para la concepción de persona de Martínez (2008). Ambos dejan de lado el estudio del cuerpo y retoman la visión émica del ser humano rarámuri, que es la de persona.

Estas aproximaciones nos llevan al cuerpo, el cual utilizaré como metáfora del sistema social (Douglas, 1973). Pretendo entender las concepciones émicas sobre el cuerpo y la persona, pero con la finalidad de identificar y analizar la interacción entre el individuo y su entorno social. Para ello me serviré de la conceptualización de Scheper-Huges y Lock (1987) sobre el cuerpo individual, el social y el político, en su mutua implicación.

\section{Líneas teóricas}

Mary Douglas ( 1973) utiliza los límites del cuerpo como metáfora del sistema social, donde los usos del cuerpo marcan el estar dentro o fuera del grupo de referencia. Si bien puede pensarse que los conceptos rará- muri de persona y cuerpo remiten a estos límites, es importante observar que en el contexto de estudio, por ser una comunidad de reciente formación y afectada por diversos procesos (aserraderos, misión, migración, narcotráfico), estas nociones no están articuladas y no se manifiestan de manera unívoca. Por ejemplo, la idea rarámuri sobre el pecado, puesta en relación con la visión judeocristiana de Anita, resulta mucho más flexible, admite regulaciones. Y se distingue a su vez de la noción católica juvenil que llega después de Anita; de la cristiana, con los bautistas que se instalan en una ranchería; de la migración con referentes propios; y la de los sicarios, con armas y violencia. Parafraseando a Douglas, este impulso ordenador de la sociedad se modifica y enriquece continuamente. Las dimensiones simbólicas del cuerpo son dinámicas, por ello se verá en perspectiva a las tres generaciones.

Utilizaremos el enfoque de Scheper-Hughes y Lock (1987) por su dinamismo, que ayuda a dar cuenta de cómo el contexto y la normativa de cada época marca las formas del matrimonio, dejando un margen al aspecto individual. La propuesta toma en consideración tres cuerpos: el cuerpo individual, la parte experiencial y volitiva de la persona, que conlleva sus decisiones personales con lo dado y construido; el cuerpo social, que se refiere a la significación del cuerpo en términos de metáfora con respecto al sistema social; y el cuerpo político relativo a la normatividad. No obstante, esta separación es meramente heurística, pues los tres se implican unos a otros. Con base en Mary Douglas, Eroza (2016: 102) apunta que:

Dada la virtud de simbolizarse mutuamente (el cuerpo y la sociedad) en particular frente a situaciones de crisis, los tres cuerpos confluyen para resaltar las fronteras culturales que buscan pautar el comportamiento, pero también las tensiones existentes entre el individuo y su entorno social.

El cuerpo individual, es decir, la experiencia vivida en el propio cuerpo, se encuentra en el campo de las percepciones y las sensaciones corporales, interpretadas desde la cultura, aunque no de forma unívoca, pues el cuerpo posee también capacidad de agencia: experimenta y responde a la experiencia y a los constreñimientos que la sociedad le impone.

La comunidad, junto con todos los que la integran, representa el cuerpo social: los jóvenes, los maestros, los sacerdotes, el mayora, las tenanches... Son sobre todo cuerpos simbólicos que se comparten con varios individuos, es la interacción social, la negociación de la formación de parejas. Este cuerpo no es homogéneo. 
El cuerpo político es la regulación y reglamentación de las interacciones del cuerpo social e individual. Se manifiesta en el control y la vigilancia. Por ejemplo, las mujeres sólo toman tesgüino en fiestas; en cambio los hombres pueden tomar otras bebidas alcohólicas aunque no sea fiesta (lo cual no es bien visto, pero se hace igualmente). Tenemos así que las mujeres están normadas y simbolizan a la comunidad; son parte del cuerpo político.

La teoría de los tres cuerpos resuena con el postulado fenomenológico de Schütz (1993: 38) según el cual la realidad es un mundo en el que los fenómenos están dados, sin importar si son reales o no. El mundo de la vida cotidiana se considera una actitud natural desde el sentido común:

Esta actitud frente a la realidad permite a los sujetos suponer un mundo social externo regido por leyes, en el que cada sujeto vive experiencias significativas y asume que otros también las viven, pues es posible ponerse en el lugar de otros; desde esta actitud natural el sujeto asume que la realidad es comprensible desde los conceptos del sentido común que maneja, y que esa comprensión es correcta [Schütz, 1993: 39].

\section{Las tres generaciones}

Referir generaciones me permite buscar la experiencia de conjunto de aquellos que comparten una posición sobre el arrejuntamiento y la construcción del cuerpo, con respecto a la Misión. Para el estudio intergeneracional entenderé como generación al "conjunto de los coetáneos que tienen experiencias comunes fuertes" en un mismo contexto sociogeográfico, lo que implica un destino en común (Donati, 1999).

Las generaciones están delimitadas por las fechas en las que se arrejuntaron. En la primera generación la vida estaba marcada por la agricultura, el pastoreo y los aserraderos; Anita influenció las transformaciones de algunas perspectivas. En la segunda, sigue presente la siembra y el pastoreo, ya no hay aserraderos y la migración estacional y definitiva son opciones de vida para mucha gente de la comunidad; las comunidades misioneras de jóvenes tienen una presencia menos autoritaria que la de Anita, con intentos de proyectos productivos. La tercera generación vive la experiencia de la migración, ya sea estacional o definitiva, $\mathrm{y}$ algunos son empleados por el narco; se reduce el número de misioneros y son coordinaciones heterogéneas de personas no necesariamente ligadas a lo religioso, que intentan cortar con el asistencialismo (véase cuadro 2 ).

\section{Primera generación: llegada de Anita 1952-1986}

La gente se dedica principalmente a la agricultura y al cuidado de sus animales. Los aserraderos toman importancia, atraen nuevos pobladores y dictan el desplazamiento o movilidad de la gente.

Con la llegada de Anita se empieza a alfabetizar a la población, les enseña castilla. Anita construyó la iglesia, la escuela y un dispensario médico. Tenía varios niños internados para que aprendieran a leer y escribir, alfabetizó a varias generaciones. Enseñaba también a los adultos, aunque a las mujeres les pedía ayuda para limpiar, cocinar y atender a los niños. Un día una mujer rarámuri murió de parto, y Anita adoptó a la bebé. No obstante, para poder hacerlo tuvo que contratar la ayuda de una adolescente, pues Anita era paralítica. Varias mujeres de la primera y de la segunda generación pasaron por este cargo.

En 1973, cuando Anita estaba al frente de la MIB, llegó el segundo aserradero. Además de generar empleo

Cuadro 2. Generaciones en estudio

\begin{tabular}{lll}
\hline \multicolumn{1}{c}{ Generaciones } & \\
\hline \multicolumn{1}{c}{ Primera } & \multicolumn{1}{c}{$\begin{array}{c}\text { Segunda } \\
\mathbf{1 9 8 6 - 2 0 0 1}\end{array}$} & $\begin{array}{c}\text { Tercera } \\
\mathbf{2 0 0 1 - 2 0 1 9}\end{array}$ \\
\hline Comienzo de población del lugar & Los aserraderos & La Misión \\
La agricultura y el cuidado de animales & La Misión & Migración \\
Los aserraderos & Migración & Narcotráfico \\
Las escuelas radiofónicas & & \\
La Misión de Anita & & \\
\hline
\end{tabular}


para los hombres de la comunidad, el aserradero fomentó que las mujeres comenzaran a lavar ropa y a cocinar para familias en pueblos mestizos. Así, los aserradores propiciaron la movilidad entre las comunidades. En 1975, abrieron otro en Nanagochi, población cercana a Ba'winokáachi, haciendo que varios se mudaran ahí.

Dados estos incrementos de población, los servicios se fueron ampliando. Cuando estuvieron construidas la iglesia, la escuela y el dispensario, se formó el centro rarámuri de Ba'winokáachi. Dejaron de ir a Sojáwachi a enterrar a sus muertos, se empezaron a reunir en la iglesia y una mujer donó un poco de sus tierras en Totorí para hacer el panteón. Sojáwachi quedó como centro ejidal.

A principios de los años ochenta se hizo la primera pila de agua en Ba'winokáachi y al siguiente año llegó la electricidad al centro rarámuri. Sacaron los aserraderos del ejido, la gente que estaba acostumbrada al trabajo remunerado dejó de tenerlo y el bosque quedó muy deforestado. Llegaron cristianos, dos canadienses que tenían un pequeño dispensario médico. En este contexto social e histórico surgieron los arrejuntamientos de la primera generación:

Cuando alguien se arrejuntaba, Anita los regañaba, quería que se casaran. A los rarámuri no les interesaba. Ellos se juntan en los tesgüinos. Muchos se tiraban piedritas,

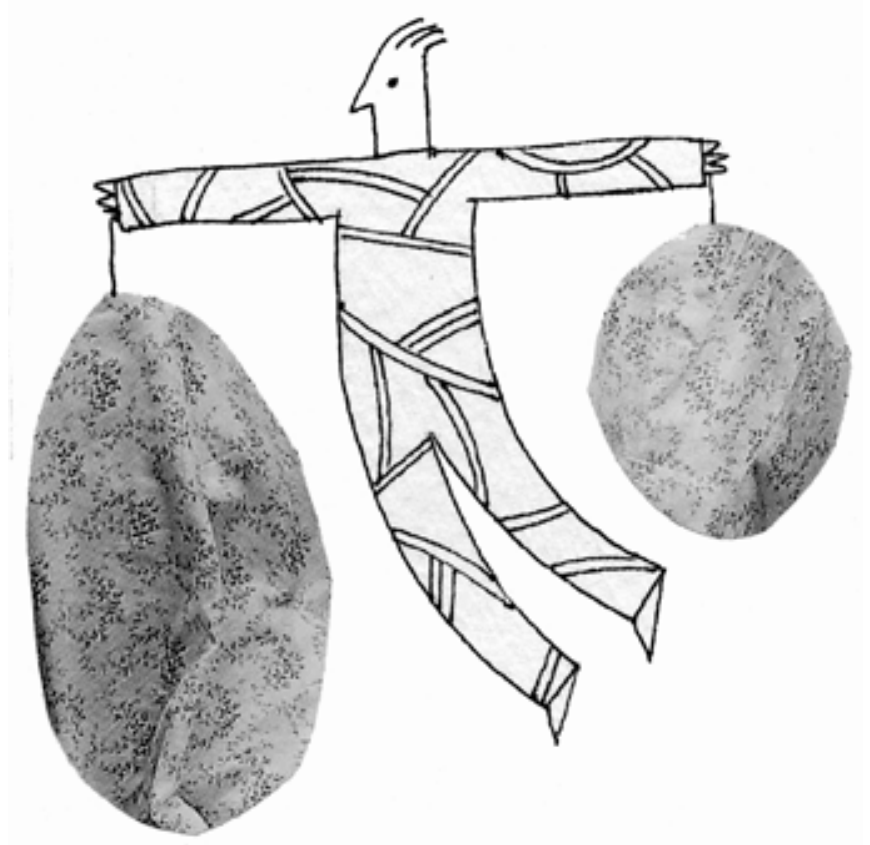

o tenían mensajeros, "dile tal cosa", eso es muy común. Llega Anita, y cambia. Empiezan a querer comulgar, el padre Javier y el padre Díaz Infante les daban la comunión por fuera, para que Anita no viera, porque decía -"tú no estás casada por la Iglesia, tú no puedes comulgar". ${ }^{3}$

Carmela fue muy cercana a la Misión, primero con Anita y luego con los jóvenes misioneros. Su matrimonio es un caso representativo de las mujeres de su generación:

Cuando era niña me mantenía cuidando borregas, vacas y marranos, tenían muchos y nos mandaban a cuidarlos. Nos llevaban a juntar maíz para encostalarlo y los acarreaba en un arrastre de palo con unos bueyes $\mathrm{y}$ toros. También tenían burros, íbamos a traer harina de saco, nos llevaban a caballo. A veces mi papá nos llevaba para San Juanito, pero en la travesía, no había trocas antes. Vivíamos trabajando, tenían tierras allá en Nanagochi, para abajo del arroyo. Ahí tenemos tierra, ya la arrumbaron, ya nadie fue a sembrar, ya se metieron ésos [a quienes] les dicen sicarios. En esas tierras luego sembrábamos chícharo y levantábamos haba, es buena tierra, no se helaba ahí.

Mi papá era el velador del aserradero que estaba en Nanagochi. Allá íbamos a veces, pero yo vivía acá con mi hermana Nacha, cuidando los niños, porque ella se iba a ordeñar las vacas, hacía queso, pero eran de mi papá las vacas y ya mandaba queso cuando hacía y le daban mandado a cambio de que cuidara. Compa Herculano, y coma Nacha, entre los dos cuidaban las vacas. Ellos se casaron cuando yo estaba chica, los juntaron como me juntaron a mí.

Platican nomás los papás de los dos, les daban nawésari. ${ }^{4}$ Los papás dijeron que se juntaran, que no se pelearan, que vivieran toda la vida juntos. A mí también así me dijeron, nos ponían sentados, a nosotros nos juntó el comisario, la mamá de Reynaldo y mi papá. Conocí a Reynaldo en la escuela, ya entré grande por eso no estudié, y ya no me dejó mi papá aquí en la escuela con Anita.

Primero tuve un novio, el esposo de Crucita, Rito se llamaba, nada más que pues no... Ya me iba a casar, Anita era la que le iba a hablar al padre, nomás que mi papá no quiso que me juntara con él, porque Rito era muy loco. A Rito lo conocí en la escuela también, pero ya después Reynaldo y yo nos platicamos. Reynaldo tenía otra novia, nada más que ya no la quería a ella, era una de aquí de Górachi. Se llamaba Carolina, también era ahijada

3 Entrevista con Manuel Franco Jáuregui (“Chiquilín”), hermano marista, el 4 de septiembre de 2013 en Guadalajara, Jalisco.

4 Consejo de la autoridad moral (pueden ser los gobernadores o iserígame o los ancianos) hacia la comunidad o, en este caso, hacia los que se juntan. 
de Anita, estaba en la escuela. Reynaldo ya no la quiso, platicaba conmigo y ya, sabe por qué ya no la querría a ella.

Con Reynaldo duré casi un año platicando, él iba a Cerro Pelón. Mi papá sí me daba permiso de platicar con él. Con Rito no me daban permiso, con ése no, a mi papá no le gustó, no lo quería porque se mantenía como así loco, ahí enojado con cualquiera. Con Rito nomás platicaba, pero siempre Anita nos quería casar, pero mi papá no quería. Con Anita no duré casi nada en la escuela, pero yo estuve en la Radiofónica, ${ }^{5}$ allá en Cerro Pelón, con eso aprendí poquito, cuando estaba chica y ya me vine con Anita un año, segundo de primaria nomás eso estudié, sí sabía escribir, las cuentas también, pero ahora ya no sé. Lástima.

$\mathrm{Al}$ año de platicar me junté con Reynaldo, no me acuerdo qué día nos juntamos. Me acuerdo que había tesgüino, ${ }^{6}$ pero ya estaban buenos y sanos. Ya no estaban borrachos y ya se quedó Reynaldo, en la casa de mi papá. Ahí vivimos un tiempo, ya luego hicimos nuestra casa, después nos fuimos a Egochi y luego nos venimos a Ba'wino por los lepes que venían a la escuela, por eso nos habló Anita. ${ }^{7}$

El cuerpo social de la primera generación está permeado por la vida alrededor de la agricultura, el cuidado de los animales, la presencia de los aserraderos, se hablaba rarámuri y había alta mortalidad infantil. La mamá de Carmela tuvo 12 hijos, y ella sólo habla de cinco vivos.

Otra característica de la primera generación que nos dibuja Carmela es el analfabetismo. En la comunidad no había escuela, a algunos los mandaban a Sisoguichi con las religiosas y los religiosos. Las dinámicas familiares cambiaron cuando la primera generación tuvo acceso a la educación. Carmela menciona las Escuelas Radiofónicas, en las que la educación tuvo mucho alcance.

La ausencia de caminos y las caminatas largas por veredas para llegar a San Juanito son también aspectos importantes de este tiempo. Los arrejuntamientos eran sobre todo entre los rarámuri de la misma comunidad o de comunidades vecinas adonde se podía llegar caminando. El promedio de edad para juntarse era los 18 años. Los padres de los dos jóvenes que se van a juntar son quienes dan consejo o nawésari "los papás dijeron que se juntaran, que no se pelearan, que vivieran toda la vida juntos. A mí también así me dijeron". El consejo, aunque no lo da el mayora, ${ }^{8}$ porque no hay, lo dan autoridades, los padres.

La mayoría de las mujeres entrevistadas de la primera generación cuenta que sus papás o el mayora escogieron a su pareja y, en un tesgüino, los hincaron y les dieron consejo. Otras pocas dicen que ellos mismos se juntaron (véase cuadro 3).

\section{Segunda generación: consolidación de la Misión 1986-2001}

El contexto en el que se arrejunta la segunda generación es la presencia evangelizadora de Anita durante 34 años, la consolidación de la Misión Indígena Ba'winokáachi con sus nuevos coordinadores laicos y la desaparición de los aserraderos, que fueron la fuente de empleo y, por lo tanto, de movilización de las familias. La segunda generación nos habla de una constante y profunda relación con la MIB y de las primeras migraciones.

La Misión consolida proyectos productivos de mermelada, carpintería y orfebrería, también comienza el equipo de maestras indígenas en la escuela y el equipo de promotoras de salud comunitaria del proyecto de salud de la diócesis. En paralelo, se dan las primeras migraciones de trabajo a ciudades del estado y a los campos menonitas.

Agustina cuenta que migró a los 12 años a la ciudad y en uno de sus regresos la juntaron; varios de sus hijos se han muerto y los que le quedan vivos están fuera de la comunidad. Tiene gran número de fotos de cuando era joven y trabajaba de cocinera en la Misión,

Cuadro 3. Los tres cuerpos en la primera generación

\begin{tabular}{llll}
\hline Generación & Cuerpo individual & Cuerpo social & Cuerpo político \\
\hline $\begin{array}{l}\text { Primera } \\
\text { Los de antes }\end{array}$ & $\begin{array}{l}\text { Sesgado a la opinión de los } \\
\text { padres, no hay mucho margen } \\
\text { para las decisiones personales }\end{array}$ & $\begin{array}{l}\text { Agricultura, aserraderos, } \\
\text { Anita y su concepción }\end{array}$ & $\begin{array}{l}\text { Aventar piedritas a quien les } \\
\text { judeocristiana antes los mayora jun- } \\
\text { taban a las parejas, ahora los } \\
\text { padres de los jóvenes }\end{array}$ \\
\hline
\end{tabular}

5 Escuelas radiofónicas, intervención educativa jesuita, simultánea al proyecto de alfabetización de Anita.

6 Bebida de maíz fermentado.

7 Entrevista con Carmela Terrazas, primera generación, el 10 de octubre de 2013, Ba'winokáachi, Sierra Tarahumara, Chihuahua.

8 Cargo tradicional rarámuri que consiste en cuidar de las mujeres y los niños, y de juntar a las parejas. 
así como de sus hijos pequeños en el internado. Le regalaron un hijo, ella lo crió:

Yo sí estudié poquito pero no aprendí, entré en el internado, porque antes daba mucha hambre; ahí daban puro arroz y agua. Me empaché una vez. Dicen "qué buena gente era Anita”, isi era bien brava! Yo por eso ya no regresé a la escuela. Mi muchacha sí estudió ahí, pero se murió después. Yo estuve en el internado y me arranqué a mi casa. Más grande salí a trabajar a Chihuahua, pues quién me iba a dar comida de 12 años, ahí estuve un año, en Chihuahua con una señora, ya después me vine y ya me casé aquí, ya no me dejaron ir, mi mamá no me dejó, porque duraba mucho sin venir. Me casé a los 14, yo no quería casarme pero mi mamá me dijo que me casara. Yo todavía no quería, tenía mucho miedo. Sí daba miedo, Juan me dejaba con 11 años, tendría 26 años, por ahí, ansina, era cuñado de mi hermana Florinda, hermano de Felizardo. Me dijo mi hermana que me casara con él porque él era muy trabajador quién sabe qué.

No platicamos, no lo conocía casi, luego me llevaron para el Ojo del Buey. No sé si era casado antes o no, ahí se mantienen con muchas mujeres yo creo. Nos juntamos buenos y sanos, sin tesgüino, como yo no tomaba todavía. Él me pidió, fue a Tónachi y le pidió a mi mamá, sí extrañé Tónachi, pero ¿Qué va a hacer una? Ya no hay gente allá. Mi hermana nos juntó a Juan y a mí y mi mamá quien sabe qué le diría a Juan.

Cuando me junté me sentí bien mal, se siente bien feo. Estuvimos en Ojo un mes y luego ya venimos a vivir aquí a Ba'wino. Al año que me casé tuve hijos, Leopoldo que se murió, estaba casado en Cuauhtémoc pero no conocí a la muchacha, tenía una hija, era de Cusárare la señora. Luego tuve a Alicia, ella estuvo en el internado, ya no estaba Anita y cómo sí aprendieron bien, a ellos sí les gustaba estudiar, ahí tengo retrato yo, todo. Yo ya no me volvería a juntar. ${ }^{9}$

En el cuerpo social de esta generación resalta el analfabetismo y que, cuando se arrejuntaron, se fueron a trabajar a los campos menonitas $u$ otras ciudades, lo que provocó que muchos se quedaran a residir en esos destinos mientras otros regresaban a las rancherías. En las familias, la mitad de los hijos o un poco menos vive fuera de Ba'winokáachi. En esta generación comenzó el éxodo que se acrecentaría con la tercera generación y que desde entonces condiciona los lugares en donde los jóvenes se conocen para arrejuntarse. El cuerpo social está definido, entonces, por la ampliación de actividades económicas.
En la formación de parejas, como expresión del cuerpo social y político, la endogamia sigue siendo una constante, sólo en dos casos uno de los miembros es externo a la comunidad. En pocas ocasiones se observa que tuvieron noviazgos previos al arrejuntamiento.

Las parejas de esta generación se conocen, en su mayoría, en Ba'winokáachi; en menor medida se conocen trabajando en pueblos más grandes y en ciudades. El tiempo que platican empieza a ser más largo, alrededor de un año, mientras que en la generación anterior lo usual eran meses o semanas. En cuanto a la normatividad, deja de ser común el pedir permiso a los papás para juntarse, cada vez es más frecuente que, sin previo acuerdo de las familias, se vayan los novios al monte o a la casa de alguno de los dos.

En la primera y la segunda generación se establece como expresión del cuerpo social-político un escenario donde se conocen o se juntan, por ejemplo, en las carreras, o cuando el cortejo se da en la coyuntura de ser fiestero y mandar hacer pinole a aquella que le parece la más trabajadora, virtud muy apreciada entre los rarámuri. A su vez, la Misión y la escuela dejan de ser espacios donde se conocen las parejas. Al igual que en la primera generación, es recurrente que las parejas de hermanos de una familia con hermanas de otra familia refuercen los lazos del tejido social durante las actividades agrícolas o festivas. Es una práctica que optimiza el cuerpo social, en la cual no necesariamente interviene el cuerpo político, y en cambio sugiere una expresión de la agencia de cuerpos individuales.

En dos casos, mujeres que no tuvieron papá o que fueron abandonadas por sus padres, se vieron obligadas a que juntarse desde muy pequeñas con el hombre que las pretendía, ya que estaban desprotegidas. El cuerpo social y político no les dejaba otra opción porque, de otra manera, ¿quién se haría cargo de ellas? Así que fueron juntadas a temprana edad, el muchacho habló con los tutores de las menores. Ellas dijeron que no fueron consultadas, sólo un día les avisaron que se juntaran con tal o cual hombre. Se muestra una confabulación del cuerpo social-político, que no da cabida al cuerpo individual.

Esta generación parece dar cuenta de una tensión entre los cuerpos individual, social y político, que es resultado de la transición generacional. De las mujeres entrevistadas, la mitad no quería juntarse. Algunas, como en este caso, ni habían platicado con el hombre en cuestión, y es común que fuera mayor que ellas. El cuerpo social y el político siguen rigiendo. Aunque cabe rescatar que, desde el cuerpo individual, registré casos

9 Entrevista con Agustina Salido, segunda generación, 31 de octubre de 2013, Ba’winokáachi, Sierra Tarahumara, Chihuahua. 


\section{Cuadro 4. Los tres cuerpos en la segunda generación}

\begin{tabular}{llll}
\hline Generación & Cuerpo individual & Cuerpo social \\
\hline $\begin{array}{l}\text { Segunda } \\
\text { Nasipa }\end{array}$ & $\begin{array}{l}\text { Entre la opinión de los padres } \\
\text { y la decisión personal }\end{array}$ & $\begin{array}{l}\text { Migraciones estacionales, } \\
\text { la Misión llevada por laicos }\end{array}$ & $\begin{array}{l}\text { La norma no dicha es } \\
\text { juntarse en los tesgüinos }\end{array}$ \\
\hline
\end{tabular}

de migración a las ciudades en los que empiezan a juntarse lejos de las familias, haciéndose más presente su decisión personal.

\section{Tercera generación: migración, alcoholismo y narcotráfico 2001-2020}

Esta etapa comienza con el antecedente de la desaparición de los aserraderos como factor detonante de la migración. Es común que los jóvenes vayan a los campos de manzanas en Cuauhtémoc y sus alrededores, como Rubio o alguno de los campos menonitas. Este trabajo temporal se realiza en momentos muy específicos del ciclo del cultivo de manzana, como el desahije y la pizca. Algunos más salen a trabajar a Chihuahua, Namiquipa y otras ciudades del estado.

En esta tercera generación, la vida migratoria comienza a tomar fuerza, cada vez más jóvenes salen de la comunidad para no volver. Quienes regresan van una o dos veces al año, sobre todo durante las fiestas como la Semana Santa, el 12 de diciembre que festejan a la Warupa o el 16 de septiembre que agradecen los primeros frutos de la cosecha. Esta migración ha sido de hombres y mujeres. Los varones se ocupan en trabajos de albañilería y las mujeres en el trabajo doméstico y el cuidado de niños en las ciudades, mientras que los campos de manzanas captan tanto a hombres como a mujeres.

No sólo el consumo de alcohol creció y se transformó, también empezó a cobrar fuerza el consumo de drogas en la comunidad, así como la venta de pornografía au diovisual. Pese a que la presencia del narcotráfico en la sierra es sabida desde hace más de tres décadas, ésta no había llegado a la región de Ba’winokáachi. Las siembras de marihuana y amapola se han acercado a la Alta Tarahumara y, en consecuencia, los jóvenes han empezado a trabajar en las pizcas de "la hierba".

Con respecto al matrimonio, la Misión propició, sin que fuera su objetivo, parejas interculturales. En esta etapa se forman tres parejas interculturales de misioneras de la ciudad que se juntaron con muchachos de la comunidad. Las reglas de la homogamia se flexibilizan, después de tantos años de intervención. Asimismo, por las tendencias de movimiento y migración, la exogamia empieza a ser más común, incluso un poco más que la endogamia. La cantidad de noviazgos aumenta antes de arrejuntarse y, como todavía son jóvenes, sólo aparece que han tenido un arrejuntamiento; en el futuro se verá si éstos son duraderos y únicos. La edad promedio de arrejuntamiento sube un año respecto de las generaciones anteriores.

Es interesante que, con excepción de dos personas, ninguno respondió haberse juntado por razones prácticas como en las generaciones pasadas. Quizá por influencia de los misioneros que comparten sus maneras de relacionarse y de estar en pareja, de los medios de comunicación y por las salidas a las ciudades. En este sentido, la mayoría de las veces los chicos se conocen fuera de su comunidad. Además, el tiempo de platicar, es decir de noviazgo, aumenta considerablemente.

Marisa es un ejemplo representativo de la tercera generación; se fue a trabajar a Chihuahua porque tenía una tía allá. Pasaba una semana de vacaciones en casa de sus papás en El Rincón. En la ciudad conoció a un muchacho de la sierra, de una zona muy lejana a su comunidad, y se casó con él. Sus papás se enteraron años después. En este caso, los padres no tuvieron incidencia alguna en la decisión para elegir la pareja. Al irse a Chihuahua, el cortejo fue en un parque, y Marisa describe cómo el celular permea las relaciones de la última generación y se empieza a desarrollar el prototipo de amor romántico. ${ }^{10}$

Omar y Yésica son de la comunidad, de rancherías muy cercanas, estos dos jóvenes se juntaron. Ella de El Rincón, él de Ba'winokáachi, tuvieron una hija. Él empezó a trabajar con los sicarios, lo que lo alejó de Chihuahua. Yésica ya tiene dos años viviendo en la casa de sus suegros, Omar ha visto muy poco a su hija y hace dos años que no regresa. Yésica ya hizo un acuerdo con los papás de Omar, que si él no regresa en un tiempo más, ella y su hija retornarán a El Rincón con su familia materna. Aquí se corrobora cómo la falta de empleo y la reciente entrada del narcotráfico a la Alta Tarahumara están afectando la composición de las familias.

${ }^{10}$ Entrevista con Marisa Batista, tercera generación, 10 de septiembre de 2013 en El Rincón, Ba’winokáachi, Sierra Tarahumara, Chihuahua. 
La normativa o cuerpo político dicta que las parejas se junten, no obstante, las nuevas situaciones que cierto tipo de trabajos traen a las familias y a las parejas hace que la normativa se flexibilice. Esto reconfigura el cuerpo social, el contexto y la manera en que se toman decisiones. Los ámbitos laborales generan constreñimientos y tensiones inéditos.

Los padres se enteran años después de que sus hijos se juntaron, y esto ocurre, por lo general, cuando en ocasión de alguna fiesta las o los jóvenes regresan a sus rancherías de origen. El cuerpo social se ha ampliado y, por ende, distintos cuerpos políticos entran en disputa, unos apuntan a la tradición y otros se rigen por las pautas urbanas norteñas, donde el noviazgo es más común y, debido a las dinámicas de la ciudad, el uso de celular es una constante. La norma de que los padres aprueben, se les pida permiso y den consejo se ha transformado por completo. Ello demuestra la ampliación del cuerpo social, que responde al contexto migratorio en el que los jóvenes están inmersos, y a los rumbos que van tomando individualmente.

Estos jóvenes conocen la vida del campo, saben sembrar y cuidar ganado, sin embargo, en la vida adulta trabajan en las ciudades, en algún OXXO de Chihuahua o como trabajadoras domésticas, como albañiles o en los campos menonitas. Crecen en un contexto rural agrícola que no les ofrece opciones de vida, por lo que terminan desenvolviéndose en otros ámbitos, donde se relacionan con sus parejas y se arrejuntan. Aumenta su campo de decisión en la elección de pareja, lo cual disminuye la opinión y elección de los padres, la familia y la normatividad comunitaria. En cuanto al cuerpo político, deja de tener peso, pues la mayoría de las parejas se forma fuera de la comunidad. El uso del celular abona al cuerpo individual, ya que de algún modo no son vistos conversando, es más privado que platicar o mirarse. El celular otorga nuevas posibilidades para el romance.

Todo esto condiciona los arrejuntamientos y los posiciona entre el libre albedrío y el uso de las leyes, normas o costumbres de juntarse. En esta generación hay libertad y autonomía al escoger pareja, quien a su vez tiene más opciones que sus padres o abuelos. En las ciudades hay mayor apertura. En muchos casos, el mercado laboral tiende a violentar los arrejuntamientos y a reconstruirlo de nuevas maneras (cuadro 5).

\section{Conclusiones}

La Sierra Tarahumara ha sufrido cambios drásticos en el último siglo. Mostramos cómo los cambios de contexto se ven reflejados en los procesos de arrejuntamiento de tres generaciones recientes de Ba'winokáachi.

Dentro de las historias de vida se repiten ciertos patrones del orden social: uno es la presencia del tesgüino como fiesta. El tesgüino es un espacio cultural importante para los arrejuntamientos, entendidos como la unión afectiva-sexual de una pareja y se suma a espacios tales como el pastoreo, las actividades agrícolas, festividades religiosas, bailes, en las ciudades de destino migratorio o en las pizcas. Otra situación invariable es la alta mortandad, más frecuentemente de niños pequeños, seguida de fallecimientos de adultos por accidentes, por epidemias o por muerte "de tesgüino”, es decir, de borrachera. Esto crea a las/os viudos. Por otra parte, está la práctica común de tener entenados o regalar a los propios hijos, que desafía el concepto de propiedad privada. Estos tres factores -el tesgüino y lo que hay alrededor de él, el alto índice de decesos infantiles y de adultos y la práctica de los hijos regalados-permanecen y forman parte del cuerpo social a través de las generaciones, ya sea mediando o condicionando los arrejuntamientos.

Hay también elementos que han mutado con el tiempo, uno muy significativo es el uso de la lengua rarámuri, que paulatinamente ha dejado de hablarse. Otra fuerte transformación debida a los giros en los contextos de los arrejuntamientos son las actividades laborales, que primero estuvieron dentro de la comunidad y después se fueron alejando a las ciudades. Y, por último, la Misión ha tenido cambios que a lo largo de las coordinaciones han incidido en la vida de la comunidad, y que van desde insistir en que se casaran (Anita) y aconsejar con quien juntarse, hasta juntarse con los de la comunidad (las misioneras).

Conforme pasan las generaciones, la endogamia de las parejas se reduce. Las parejas de la primera generación están conformadas por personas de rancherías de la misma comunidad o de comunidades vecinas. En las siguientes generaciones las parejas son de lugares cada vez más lejanos como las ciudades. De igual modo, con el paso del tiempo, aumenta el número de noviazgos previos al arrejuntamiento.

\section{Cuadro 5. Los tres cuerpos en la tercera generación}

\begin{tabular}{llll}
\hline Generación & Cuerpo individual & Cuerpo social & Cuerpo político \\
\hline $\begin{array}{l}\text { Tercera } \\
\text { Los nuevos }\end{array}$ & $\begin{array}{l}\text { Decisiones independientes de la } \\
\text { familia }\end{array}$ & $\begin{array}{l}\text { Migración, pizcas, narco- } \\
\text { tráfico }\end{array}$ & $\begin{array}{l}\text { Una normativa distinta, } \\
\text { adecuada a la vida de la } \\
\text { ciudad }\end{array}$ \\
\hline
\end{tabular}


Otro cambio gradual son las razones por las que se juntan. Los más antiguos se arrejuntaban por razones prácticas de la vida como "necesito un hombre para que me traiga leña o necesito a una mujer para que me cocine". Los de en medio empiezan a hablar de cualidades personales y físicas, mientras que la última generación está más centrada en "el amor” romántico occidental, destacando las cualidades y actitudes del otro como "me trataba muy bien" o "me decía cosas que jamás voy a olvidar”.

Al ser visto de manera generacional, emerge el gran cambio sufrido por el cuerpo social, político e individual. Los abuelos se pronuncian sobre lo distinto que los jóvenes se juntan ahora, pensando que el pasado siempre fue mejor, "ahora usan grabadora, y en los tesgüino y andan ahí bailando”. Los referentes de los abuelos son distintos, así como sus valores, lo que para los jóvenes es divertido, a los ancianos les parece una falta de respeto.

La presencia de los padres en los arrejuntamientos disminuye a través de las generaciones. En la primera son ellos quienes acuerdan el arrejuntamiento. En la segunda, las parejas deciden juntarse y algunos empiezan a juntarse fuera de la comunidad, en ambos casos siguen recibiendo el consejo paterno, dejando de manifiesto la confluencia de los cuerpos social e individual, pero también el político, en la medida en que los valores intergeneracionales se disputan, negocian, cambian. En la tercera generación, los jóvenes abandonan las comunidades por falta de empleo y se arrejuntan fuera; los padres conocen años después a sus nueras y yernos.

La edad promedio en las tres generaciones para arrejuntarse por primera vez son los 18 años. En la primera generación la gran mayoría se conocieron con Anita, en el centro rarámuri, ya sea yendo a la escuela, a la tienda o a rezar a la iglesia. La mitad de segunda generación se conoció con Anita o en la comunidad, y la otra mitad en las pizcas o en el trabajo en las ciudades. En la tercera, la mayoría inicia sus
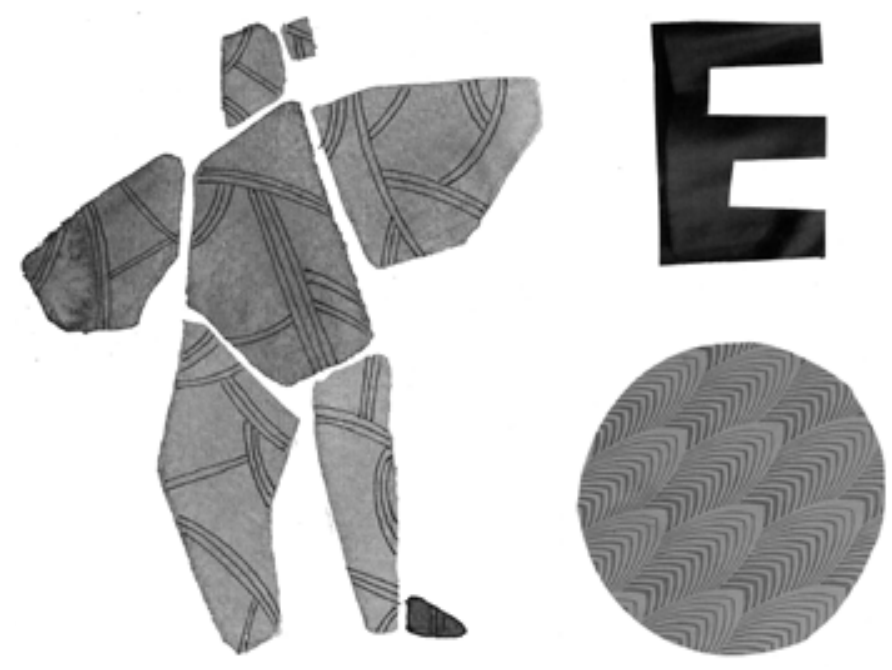

contactos fuera, sobre todo en las pizcas, y el narcotráfico empieza a influir en las relaciones de pareja.

La libertad y la desenvoltura, por un lado, y la aceptación del destino y su inevitabilidad, por otro, son lo que, me parece, ha caracterizado los cuerpos en la visión del mundo rarámuri. Las separaciones son permitidas, aunque no son lo común. Cada cual acepta "lo que le tocó”, y así "cumplen” con lo que les corresponde. Cumplir es muy importante en la cultura, desde el cargo de la fiesta hasta criar a los hijos o no pelear con el esposo.

Los hallazgos alrededor de cada cuerpo pueden resumirse como se muestra en el cuadro 6 .

El cuerpo individual no es lo que aparece a simple vista. Entendido como la parte de la experiencia personal, depende del momento histórico, está cruzado con el curso de vida. Son las decisiones personales frente al contexto macro. En las dos primeras generaciones fue difícil encontrar el cuerpo individual, porque estaba mediado por el cuerpo social y la normatividad del cuerpo político. Este cuerpo individual tiene más cabida en la última generación, en la cual los jóvenes eligen a su pareja sin intervención de la familia.

Cuadro 6. Los tres cuerpos a través de las generaciones

\begin{tabular}{llll}
\hline $\begin{array}{c}\text { Cuerpos/ } \\
\text { generaciones }\end{array}$ & \multicolumn{1}{c}{$\begin{array}{c}\text { Primera } \\
\text { Los de antes }\end{array}$} & $\begin{array}{c}\text { Segunda } \\
\text { Nasipa }\end{array}$ & $\begin{array}{c}\text { Tercera } \\
\text { Los nuevos }\end{array}$ \\
\hline Cuerpo individual & Sesgadoa la opinión delos padres & $\begin{array}{l}\text { Entre la opinión de los } \\
\text { padres y la decisión libre }\end{array}$ & $\begin{array}{c}\text { Decisiones independientes } \\
\text { a la familia }\end{array}$ \\
Cuerpo social & Agricultura, aserraderos & Misión, migraciones & Migración, narcotráfico \\
Cuerpo político & Piedritas & Tesgüino & Pizcas \\
\hline
\end{tabular}


Los cuerpos social y político son los que más saltan a la vista. Las historias, el contexto social que se vivía, los empleos, la opinión y la decisión de la familia, así como los consejos de la misma, son parte esencial de este cuerpo. Por ejemplo, la familia "la obligó a juntarse con el muchacho", o "no tenía marido, pues me tuve que juntar". Y es muy claro en los casos repetidos en que dos hermanos de una familia con dos hermanas de otra familia se fortalecen y se da continuidad a los lazos sociales y familiares que ya de por sí existen. El ideal de pareja deseable se va modificando.

Respecto al cuerpo político, la norma es que un hombre y una mujer no pueden platicar en público si no son pareja. Sin embargo se crean mecanismos con los cuales romper estas reglas: en la primera generación las piedritas que se aventaban para quedar y platicar en el bosque, lejos de quienes los pudieran ver. Otro mecanismo, ya institucionalizado, son los tesgüinos, en los que la bebida "relaja los cuerpos" y las normas. Las piedritas y los tesgüinos, transversalmente, se convierten en regla para romper la norma según la cual las mujeres y los hombres no pueden conversar en público.

La coexistencia es la parte más importante de los tres cuerpos. Estos cuerpos se interrelacionan y dialogan unos con otros en un constante ir y venir. El cuerpo político que prohíbe y permite ciertas cosas es burlado mediante transgresiones sociales que se superponen a esta normativa, que a su vez se convierte en regla no dicha. Hablo de la regla que dicta que los hombres y las mujeres no arrejuntados no pueden hablar; para esto se crea el tesgüino, donde la norma se relativiza y donde se da el cortejo y los arrejuntamientos. Como éste, hay muchos ejemplos donde los cuerpos se involucran unos con otros.

Finalmente, en el tránsito de las generaciones, coexisten varias fronteras del cuerpo, que son heterogéneas y complejas. Al convivir entre ellas y crear situaciones donde las personas transitan, estas fronteras coinciden y se van combinando. A veces se encuentran y la convivencia se vuelve más complicada, mientras que en otras logran mantener cierta armonía retomando aspectos que les son útiles. Así se construye el tránsito y la diversidad de cuerpos sociales: el judeocristiano impuesto por Anita, el rarámuri tradicional, el de las ciudades al migrar, el de los misioneros católicos, el de los menonitas, el de los cristianos bautistas.

Las experiencias narrativas a menudo dan cuenta de la complejidad de nuestra experiencia en el marco de la sociedad y la cultura. Por tal razón, nos revelan con claridad que, aunque la distinción entre los tres cuerpos resulta de gran utilidad para fines analíticos, en el marco de las experiencias documentadas no siempre es sencillo precisar las demarcaciones entre la tríada. En suma, los cuerpos se interrelacionan todo el tiempo, en distintas situaciones, sin perder de vista que hay aspectos que los particularizan.

\section{Fuentes}

ACUÑa, ÁNGEL

2006 La construcción cultural del cuerpo en la sociedad Rarámuri de la Sierra Tarahumara, AbyaYala, Quito.

Donati, Pier PaOlO

1999 "Familias y generaciones”, en Desacatos, núm. $2,<$ http: / / www.ciesas.edu.mx/desacatos / 02 $\%$ 20Indexado/Saberes_2.pdf> [20 octubre de 2013].

DOUglas, Mary

1973 Pureza y peligro. Un análisis de los conceptos de contaminación y tabú, Siglo xxi de España Editores, Madrid [1970].

ERozA, ENRIgUe

2016 El cuerpo como texto y eje vivencial del dolor: las narrativas del padecimiento entre los Chamulas, Centro de Investigaciones y Estudios Superiores en Antropología Social-Publicaciones de la Casa Chata, México.

Fujigaki, Alejandro

2005 Muerte y persona: Ensayo sobre rituales mortuorios en una comunidad de la Sierra Tarahumara, Universidad Autónoma de Morelos-Facultad de Humanidades, México.

Guillén, Héctor e Isabel Martínez

2005 "Del cuerpo a la persona: ensayo sobre una noción rarámuri”, tesis de licenciatura en Antropología Social, Universidad Autónoma del Estado de Morelos, Cuernavaca.

MARTÍNEZ, ISABEL

2008 "Los caminos rarámuri. Persona y cosmos en el noroeste de México", tesis de maestría en Antropología, Universidad Nacional Autónoma de México-Instituto de Investigaciones Antro-

MaUss, MARCEL pológicas, México.

1979 "Técnicas y movimientos corporales", en Sociología y antropología, Madrid, Tecnos, pp. 335-356.

Salazar, Denisse

2006 "La explotación forestal en la Sierra Tarahumara. Significación social del trabajo industrial de los aserraderos de San Juanito, Chihuahua", ponencia presentada en $V$ Congreso Nacional AMET 2006 Trabajo y Reestructuración: Los Retos del Nuevo Siglo <http: / /www. izt.uam.mx/amet/vcongreso/webamet/ indicedemesa/ponencias / Mesa\%2011/ Salazarm 11.pdf> [12 de octubre 2013].

SCHEPER-Hughes, NANCY

Y MARGARET M. LOCK

1987 "The mindful body: A prolegomenon to future work in Medical Anthropology", en Medical Anthropology Quarterly, New Series, vol. 1, núm. 1, pp. 6-41.

Schütz, Alfred

1993 La construcción significativa del mundo social. Introducción a la sociología comprensiva, Paidós, Barcelona [1932]. 